\title{
Endothelial wall thickness, cardiorespiratory fitness and inflammatory markers in obese and non-obese adolescents
}

\author{
Larissa R. Silva ${ }^{1}$, Cláudia Cavaglieri² ${ }^{2}$, Wendell A. Lopes ${ }^{2}$, Juliana Pizzi ${ }^{3}$, \\ Manuel J. C. Coelho-e-Silva ${ }^{4}$, Neiva Leite ${ }^{1}$
}

\begin{abstract}
Background: Increased carotid intima-media thickness (c-IMT) is considered a marker of early-onset atherosclerosis and it has been found in obese children and adolescents, but the risk factors associated with this population remain to be elucidated. Objective: To compare and verify the relationship between c-IMT, metabolic profile, inflammatory markers, and cardiorespiratory fitness in obese and non-obese children and adolescents. Method: Thirtyfive obese subjects (19 boys) and 18 non-obese subjects ( 9 boys), aged 10-16 years, were included. Anthropometry, body composition, blood pressure, maximal oxygen consumption ( $\mathrm{VO}_{2} \mathrm{max}$ ), and basal metabolic rate were evaluated. Serum glucose, insulin, homeostasis model assessment of insulin resistance (HOMA-IR), blood lipids, C-reactive protein (CRP), and adiponectin were assessed. c-IMT was measured by ultrasound. Results: The results showed that c-IMT, triglycerides, insulin, HOMA-IR, and CRP values were significantly higher in the obese group than in the non-obese group, and high-density lipoprotein cholesterol (HDL-c), adiponectin, and $\mathrm{VO}_{2}$ max values were significantly lower in the obese group than in the non-obese group. The c-IMT was directly correlated with body weight, waist circumference, $\%$ body fat, and HOMA-IR and inversely correlated with \% free fat mass, HDL-c, and $\mathrm{VO}_{2}$ max. Conclusions: Our findings show that c-IMT correlates not only with body composition, lipids, insulin resistance, and inflammation but also with low $\mathrm{VO}_{2}$ max values in children and adolescents.
\end{abstract}

Keywords: obesity; inflammation; atherosclerosis; adolescents; fitness; physical therapy.

\section{HOW TO CITE THIS ARTICLE}

Silva LR, Cavaglieri C, Lopes WA, Pizzi J, Coelho-e-Silva MJC, Leite N. Endothelial wall thickness, cardiorespiratory fitness and inflammatory markers in obese and non-obese adolescents. Braz J Phys Ther. 2014 Jan-Feb; 18(1):47-55. http://dx.doi. org/10.1590/S1413-35552012005000133

\section{Introduction}

Obesity is independently associated with coronary atherosclerosis in young adults ${ }^{1}$. Inflammation, obesity, and insulin resistance usually occur together, as they are part of the atherosclerotic process and contribute to the development of cardiovascular diseases ${ }^{2}$. Research in the juvenile population shows a relationship between inflammatory markers and endothelial dysfunction $^{3,4}$. The elevation of C-reactive protein (CRP) is considered an indicator of inflammation and a predictor of cardiovascular diseases and diabetes ${ }^{5}$. Low concentrations of adiponectin are associated with obesity $^{6,7}$, vasculopathy, and diabetes ${ }^{8}$.

Recently, non-invasive techniques have been used in order to evaluate early markers of atherogenesis, including ultrasound assessment of the wall thickness of the endothelium ${ }^{9,10}$. This evaluation consists in measuring, by means of ultrasound imaging, the thickness of the tunica intima and tunica media of the artery $^{9}$, known as intima-media thickness (IMT). The increase in this value is considered a risk factor for coronary artery disease ${ }^{10}$ and current data shows that obese children have greater carotid intimamedia thickness (c-IMT) than healthy children, thus suggesting that they are more susceptible to cardiovascular events in adulthood ${ }^{2,3,9}$.

Some studies have examined the c-IMT in children and adolescents ${ }^{2,3}$, but few studies also verified cardiorespiratory fitness ${ }^{11}$. The diagnosis and prevention of these risk factors in childhood are important public health issues, as they allow early intervention in individuals at a higher risk of developing cardiovascular diseases during the juvenile or adult phase. Therefore, the objective of this paper was to investigate the relationships among endothelial

\footnotetext{
${ }^{1}$ Department of Physical Education, Universidade Federal do Paraná (UFPR), Curitiba, PR, Brazil

${ }^{2}$ Faculty of Physical Education, Universidade Estadual de Campinas (UNICAMP), Campinas, SP, Brazil

${ }^{3}$ Department of Physical Education, Universidade do Paraná (UNIPAR), Francisco Beltrão, PR, Brazil

${ }^{4}$ Research Center for Sport and Physical Activity, Faculty of Sports Sciences and Physical Education, Universidade de Coimbra, Coimbra, Portugal Received: 02/05/2013 Revised: 06/26/2013 Accepted: 09/06/2013
} 
dysfunction, dyslipidemia, level of cardiorespiratory fitness, and inflammatory markers in obese and nonobese subjects.

\section{Method}

\section{Participants}

The sample included 53 subjects, aged 10-16 years of age, from the city of Curitiba, PR, Brazil. Participants were divided into two groups, the obese group $(n=35)$ and the non-obese group $(n=18)$. Inclusion criteria were: a) informed consent signed by parents or guardians, b) meeting the criteria for obesity and non-obesity described below, and c) no history of regular physical activity outside of physical education classes at school. Based on body mass index (BMI) and U.S. growth charts ${ }^{12}$, participants were classified as obese $(\mathrm{n}=35, \mathrm{BMI}>\mathrm{P} 95 \%)$ and non-obese $(\mathrm{n}=18, \mathrm{BMI}<85 \%)$. The obese group was selected among participants from an intervention project conducted at Universidade Federal do Paraná (UFPR), Curitiba, PR, Brazil. The non-obese group consisted of volunteers from public schools matched by sex and age. Exclusion criteria consisted of: a) musculoskeletal problems or physical disability, b) subjects who did not undergo all assessments, c) subjects with abnormal thyroid-stimulating hormone (TSH) function. All of the adolescents and their legal guardians gave written informed consent. The study complied with Resolution 196/96 of the National Health Council and was previously approved by the Human Research Ethics Committee of the UFPR Health Sciences Faculty (CEP/SD: 945.070.10.06).

\section{Variables}

\section{Clinical evaluation}

Chronological age (CA) was recorded to the nearest 0.1 year by subtracting the birth date from the date of the mid-testing period. Sexual maturation was given by stages of pubic hair ( $\mathrm{PH})$ and was individually assessed following the criteria described by Tanner ${ }^{13}$. Resting heart rate (HRres) and systolic (SBP) and diastolic blood pressure (DBP) were measured with the subjects in the sitting position after 10 minutes of rest. HRres was obtained using a heart rate monitor (Polar A2) followed by blood pressure (BP), which was always measured by a single clinician in the right arm supported at heart level, using a mercury sphygmomanometer (Wan $\mathrm{Med}^{\circledR}$, São Paulo, SP, Brazil). Two measurements were taken, with an interval of 2 minutes between them. The lowest value was considered for the analysis. BP measurements were considered as borderline or increased if the values were equal to or above the 90th percentile for age and $\operatorname{sex}^{14}$.

\section{Anthropometry}

Height was measured with a portable stadiometer (Harpenden, Holtain Ltd, Crosswell, Crymych, Pembs., UK) to the nearest $0.1 \mathrm{~cm}$. Body mass was measured with a portable scale (Seca 770, Hanover, MD, USA) to the nearest $0.1 \mathrm{~kg}$. Anthropometry was performed by a single individual following standardized procedures ${ }^{15}$. The BMI was derived and BMI Z-score was obtained using U.S. data tables ${ }^{12}$. Waist circumference (WC) was also measured by the same single observer and was measured in centimeters, using a non-stretch flexible tape measure, to the nearest $0.1 \mathrm{~cm}$. The tape was placed above the iliac crest, parallel to the ground, with the individual standing with the abdomen relaxed, arms to the side, and feet together. The cut-off was taken as the 75th percentile or greater, according to age and ethnicity ${ }^{16}$.

\section{Body fat mass assessment}

The two-compartment model of body composition was assessed by bioelectrical impedance analysis (BIA), using a standardized body composition analyzer (Biodynamics Corporation, Seattle, WA, USA). Measurements were performed in the morning, without performing any prior vigorous physical activity and before breakfast, after a 10 to 12 hour overnight fast. The procedure required subjects to be in the supine position. Fat free mass (FFM), Fat Mass (FM), and the percentage of body fat mass $(\% \mathrm{BF})$ were calculated using validated equations ${ }^{17}$ and in accordance with National Institutes of Health guidelines ${ }^{18}$.

\section{Cardiorespiratory fitness}

Cardiorespiratory fitness was assessed on a treadmill (X-Fit 7 Power Treadmill), using protocols in accordance with age and progressive intensities. The ramp protocol was used, which consists of 8 to 12 minutes of exercise with small and constant increments in speed and gradient based on the expected maximum oxygen consumption ${ }^{19}$. Criteria for the maximum test were: a) exhaustion or inability to maintain the required speed, b) HR equal to or above $200 \mathrm{bpm}, \mathrm{c}$ ) respiratory exchange ratio (RER) equal to or greater than one. $\mathrm{VO}_{2} \max$ was determined 
by the average of the three highest consecutive values obtained during the maximum test ${ }^{20}$.

Oxygen consumption $\left(\mathrm{VO}_{2}\right)$, volume of expired carbon dioxide $\left(\mathrm{VCO}_{2}\right)$, and ventilation (VE) were measured in a gas analyzer using open-circuit ergospirometry (Parvo Medics TrueOne ${ }^{\circledR} 2400$ Metabolic Measurement System, Sandy, UT, USA), and the respiratory exchange ratio (RER) was calculated.

\section{Measurement of biochemical markers}

Participants were instructed to visit the hospital after 12 hours of fasting. All visits occurred in the morning, before any vigorous physical activity. Blood samples were collected to obtain a hemogram and levels of glucose, insulin, total cholesterol (TC), high-density lipoprotein cholesterol (HDL-c), low-density lipoprotein cholesterol (LDL-c), triacylglycerol (TAG), human adiponectin, and C-reactive protein (CRP). Data were collected by venipuncture and the blood samples were stored in dry tubes for biochemical measurements. The colorimetric enzymatic method was used to measure TC, HDL-c, and TAG. The cutoff points were those proposed to Brazilian children and adolescents ${ }^{21}$. LDL-c was calculated using the Friedewald et al. ${ }^{22}$ formula. The ultra-sensitive CRP was measured by the turbidimetric assay and adiponectin, by the ELISA method (Adiponectin DuoSet, R\&D Systems, Inc., Minneapolis, MN, USA).

\section{Intima-media thickness (IMT) assessment}

The IMT of the common carotid artery $(1-2 \mathrm{~cm}$ proximal to the carotid bifurcation) was assessed bilaterally in the posterior wall of the vessel with the aid of an ultrasound device (Philips SONOS 5500 with $8 \mathrm{MHz}$ linear transduction). The procedure required subjects to be in the supine position and resting their back on a pillow. The average of three values of the right-side c-IMT (c-IMTr) and left-side c-IMT (c-IMTl) was retained for analysis. c-IMT corresponds to the mean of c-IMTr and c-IMTl. All measurements were performed by the same experienced observer (clinician at Hospital das Clínicas - UFPR). The intraobserver coefficient was $8 \%$ for c-IMTl and $2 \%$ for c-IMTr.

\section{Statistical analysis}

The initial analysis was descriptive in nature to determine the means and standard deviations for anthropometry, metabolic markers, and IMT. The normality of data was assessed by the Shapiro-Wilk test. When necessary, values were transformed into natural logarithm $(\log n)$ for normalization. As for the proportion and prevalence, we used the chi-square test and Fisher's exact test. The independent T test was used for parametric data and the Mann-Whitney $\mathrm{U}$ test was used for nonparametric data in order to compare variables between groups. Pearson's correlation for parametric data and Spearman's correlation for non-parametric data were used to analyze the possible relationship among BMI, $\mathrm{VO}_{2}$ max, inflammatory markers, lipid profile, and c-IMT. For proper analysis, the classification of the magnitude of the correlations was used: $r=0.10$ to 0.30 (weak), $r=0.40$ to 0.60 (moderate), $r=0.70$ to 1.0 (strong). The level of significance was $\mathrm{p}<0.05$. Statistical tests were performed with the SPSS Statistics 18.0 software (SPSS Inc.).

\section{Results}

Fifty-three adolescents participated in this study and were divided into two groups according to the presence or absence of obesity. The sample consisted of 35 subjects in the obese group (19 boys and 16 girls) and 18 subjects in the non-obese group ( 9 boys and 9 girls).

The clinical and anthropometric characteristics are presented in Table 1. The mean age was similar between the obese $(12.3 \pm 1.7$ years) and non-obese subjects (12.7 \pm 1.4 years). The mean height values did

Table 1. Clinical and anthropometric variables of the obese and non-obese groups $(\mathrm{n}=53)$.

\begin{tabular}{lccc}
\hline \multicolumn{1}{c}{ Variables } & $\begin{array}{c}\text { Obese } \\
(\mathbf{N = 3 5})\end{array}$ & $\begin{array}{c}\text { Non-obese } \\
(\mathbf{N = 1 8})\end{array}$ & $\mathbf{p}=$ \\
Age(years) & $12.3 \pm 1.7$ & $12.7 \pm 1.4$ & 0.418 \\
Weight $(\mathrm{kg})$ & $75.7 \pm 20.4$ & $46.3 \pm 8.3$ & 0.001 \\
Height $(\mathrm{cm})$ & $156.2 \pm 11.1$ & $157.5 \pm 8.5$ & 0.677 \\
$\mathrm{BMI}\left(\mathrm{kg} / \mathrm{m}^{2}\right)$ & $30.6 \pm 5.8$ & $18.6 \pm 2.2$ & 0.001 \\
$\mathrm{BMIz}$ & $2.93 \pm 0.81$ & $-0.06 \pm 0.73$ & 0.001 \\
$\mathrm{WC}(\mathrm{cm})$ & $99.5 \pm 14.4$ & $67 \pm 4.8$ & 0.001 \\
$\mathrm{SBP}(\mathrm{mmHg})^{\Delta}$ & $112.3 \pm 14.6$ & $102.2 \pm 4.4$ & 0.005 \\
$\mathrm{DBP}(\mathrm{mmHg})^{\Delta}$ & $72.9 \pm 11.7$ & $74 \pm 4.5$ & 0.495 \\
$\% \mathrm{Body} \mathrm{fat}$ & $40.6 \pm 4.7$ & $24.5 \pm 7.04$ & 0.000 \\
$\% \mathrm{FFM}$ & $59.1 \pm 4.5$ & $76.1 \pm 6.6$ & 0.000 \\
$\mathrm{VO}{ }_{2} \mathrm{max}(\mathrm{ml} / \mathrm{kg} / \mathrm{m})$ & $27.7 \pm 4.17$ & $37.9 \pm 6.4$ & 0.000 \\
\hline
\end{tabular}

BMI: body mass index; BMIz: body mass index z-score; WC: waist circumference; SBP: systolic blood pressure; DBP: diastolic blood pressure; \%Body fat: percentage of body fat; \%FFM: percentage of free-fat mass; $\mathrm{VO}_{2}$ max: maximum volume of oxygen; $\Delta$ variables that did not show a normal distribution. 
not differ between groups. The obese group showed higher values for weight, BMI, BMI Z-score, and $\mathrm{WC}$ than the non-obese group $(\mathrm{p}<0.001)$ as a result of the initial group allocation. The mean SBP was higher in the obese group than in the non-obese group $(\mathrm{p}<0.005)$ and DBP did not differ between groups. As for the maturation stage, the groups were similar $(\mathrm{p}<0.59)$.

For WC, all subjects in the obese group showed increased abdominal adiposity, with 29 subjects (93\%) above the 90th percentile. None of the non-obese subjects showed adiposity above the 75th percentile. In the total sample, there were eight $(15.7 \%)$ subjects with systolic hypertensive measurements and $17(33.3 \%)$ with diastolic hypertensive measurements. The obese group had a higher frequency of hypertensive measures in SBP ( 8 vs. $\left.0, \chi^{2}=4.74 ; p<0.029\right)$. The frequencies of DBP were similar between groups. The mean values of FM, fat percentage (\%Body Fat), fat-free mass (FFM), and percentage of fat-free mass (\%FFM) were higher in the obese group than in the non-obese group $(\mathrm{p}<0.01)$. As for cardiorespiratory variables, the obese group had lower levels of $\mathrm{VO}_{2}$ max and higher levels of $\mathrm{HR}_{\text {rest }}$ than the non-obese group $(\mathrm{p}<0.001)$.

The obese group showed higher frequencies of $\mathrm{VO}_{2} \max$, lower than the expected for age and sex, than the non-obese group ( 34 vs. $14 ; \mathrm{p}<0.006$ ). In the non-obese group, three (22.3\%) subjects had normal values of $\mathrm{VO}_{2} \max$, while none of the subjects in the obese group reached this classification.

The clinical and laboratory variables are presented in Table 2. The obese subjects showed higher TAG and insulin values and lower HDL values than the non-obese ones $(\mathrm{p}<0.001)$. The TC, LDL, and glycemia (GL) variables were similar between groups.

The obese subjects had a higher number of occurrences of high TAG ( 13 vs. $\left.1, \chi^{2}=7.50 ; p<0.007\right)$ and low HDL ( 18 vs. $\left.0, \chi^{2}=17.21 ; \mathrm{p}<0.00\right)$ than the non-obese ones. TC $\left(10\right.$ vs. $\left.5, \chi^{2}=0.12 ; \mathrm{p}<0.733\right)$ and LDL ( 2 vs. $0, p<0.27$ ) did not differ between groups. Figure 1 shows the distributions of percentage values of changes in lipid profiles of both groups. The obese subjects had higher CRP, c-IMTr, and c-IMT values than the non-obese subjects $(\mathrm{p}<0.05)$ and lower adiponectin values $(\mathrm{p}<0.001)$. $\mathrm{c}$-IMTl values were similar between the two groups.

BMI showed a strong positive correlation with weight $(r=0.93 ; p<0.01)$, WC $(r=0.95 ; p<0.01)$, Fat Mass $(\mathrm{FM})(\mathrm{r}=0.95 ; \mathrm{p}<0.01)$, and \%Body Fat $(\mathrm{r}=0.87 ; \mathrm{p}<0.01)$ and an inverse correlation with $\% \mathrm{FFM}(\mathrm{r}=-0.88 ; \mathrm{p}<0.01)$ and $\mathrm{VO}_{2} \max (\mathrm{r}=-0.68$;
Table 2. Clinical and laboratory variables of the obese and nonobese groups $(n=53)$.

\begin{tabular}{|c|c|c|c|}
\hline Variables & $\begin{array}{c}\text { Obese } \\
(\mathrm{N}=35)\end{array}$ & $\begin{array}{c}\text { Non-obese } \\
(\mathrm{N}=18)\end{array}$ & $p=$ \\
\hline TC (mg/dl) & $161.9 \pm 37.5$ & $161.8 \pm 17.5$ & 0.637 \\
\hline HDL(mg/dl) & $44.7 \pm 6.8$ & $65.5 \pm 12.8$ & 0.000 \\
\hline LDL(mg/dl) & $88.4 \pm 30.6$ & $83.5 \pm 19.2$ & 0.95 \\
\hline TAG(mg/dl) & $126.6 \pm 70.6$ & $63.9 \pm 19.3$ & 0.001 \\
\hline GL(mg/dl) & $87.8 \pm 9.4$ & $85.8 \pm 4.4$ & 0.32 \\
\hline INS $(\mu \mathrm{UI} / \mathrm{ml})$ & $16.9 \pm 13.3$ & $4.12 \pm 2.3$ & 0.001 \\
\hline HOMA-IR & $3.45 \pm 3.24$ & $0.88 \pm 0.52$ & 0.001 \\
\hline $\mathrm{CRP}^{\Delta}(\mathrm{mg} / \mathrm{L})$ & $3.43 \pm 3.03$ & $1.26 \pm 0.74$ & 0.005 \\
\hline Adiponectin $(\mu \mathrm{g} / \mathrm{ml})$ & $4.65 \pm 1.85$ & $7.17 \pm 2.21$ & 0.001 \\
\hline c-IMTr(mm) & $0.43 \pm 0.04$ & $0.40 \pm 0.03$ & 0.004 \\
\hline c-IMTl(mm) & $0.43 \pm 0.05$ & $0.41 \pm 0.03$ & 0.072 \\
\hline c-IMT $(m m)^{\Delta}$ & $0.43 \pm 0.04$ & $0.40 \pm 0.02$ & 0.016 \\
\hline
\end{tabular}

TC: total cholesterol; HDL: high density lipoprotein; LDL: low density lipoprotein; TAG: triacylglycerides; GL: glycemia; INS: insulinemia; HOMA-IR: Homeostasis Metabolic Assessment; CRP c-reactive protein; c-IMTr: right intima-media thickness; c-IMTl: left intima-media thickness; c-IMT: mean intima-media thickness $\Delta$ variables that did not show a normal distribution.

$\mathrm{p}<0.01)$. It was also moderately and directly correlated with SBP $(\mathrm{r}=0.45 ; \mathrm{p}<0.01)$, HRrest $(\mathrm{r}=0.42$; $\mathrm{p}<0.01)$, TAG $(\mathrm{r}=0.42 ; \mathrm{p}<0.01), \mathrm{GL}(\mathrm{r}=0.40 ; \mathrm{p}<0.01)$, and insulin $(\mathrm{r}=0.44 ; \mathrm{p}<0.01)$ and inversely correlated with FFM ( $\mathrm{r}=0.65 ; \mathrm{p}<0.01)$, adiponectin $(\mathrm{r}=-0.51$; $\mathrm{p}<0.01)$, and HDL $(\mathrm{r}=0.61 ; \mathrm{p}<0.01)$.

The three measures of c-IMT showed a moderate direct correlation with weight, WC, BMI, FM, \%Body Fat, and FFM and an inverse correlation with $\% \mathrm{FFM}$ and $\mathrm{VO}_{2} \max$. Figure 1 shows the correlation between $\mathrm{VO}_{2}$ max and c-IMT. Only c-IMTr and c-IMT were moderately correlated with the BMI Z-score. As for laboratory variables, c-IMTr showed a weak positive correlation with LDL and GL, and a negative correlation with HDL. It was also moderately correlated with CRP. For c-IMT, we found only a weak inverse correlation with HDL. For c-IMTl, we did not find any correlations with any of the evaluated clinical and laboratory variables.

Adiponectin showed a moderate inverse correlation with weight, WC, FM, \%Body Fat, and FFM and a positive correlation with \%FFM. It was weakly and directly correlated with $\mathrm{VO}_{2} \max$. As for CRP, we found a weak direct correlation with WC and \%Body Fat and an inverse correlation with \%FFM. CRP and $\mathrm{VO}_{2}$ max were moderately and inversely correlated. As for laboratory variables, adiponectin showed moderate inverse correlation with insulinemia (INS). 

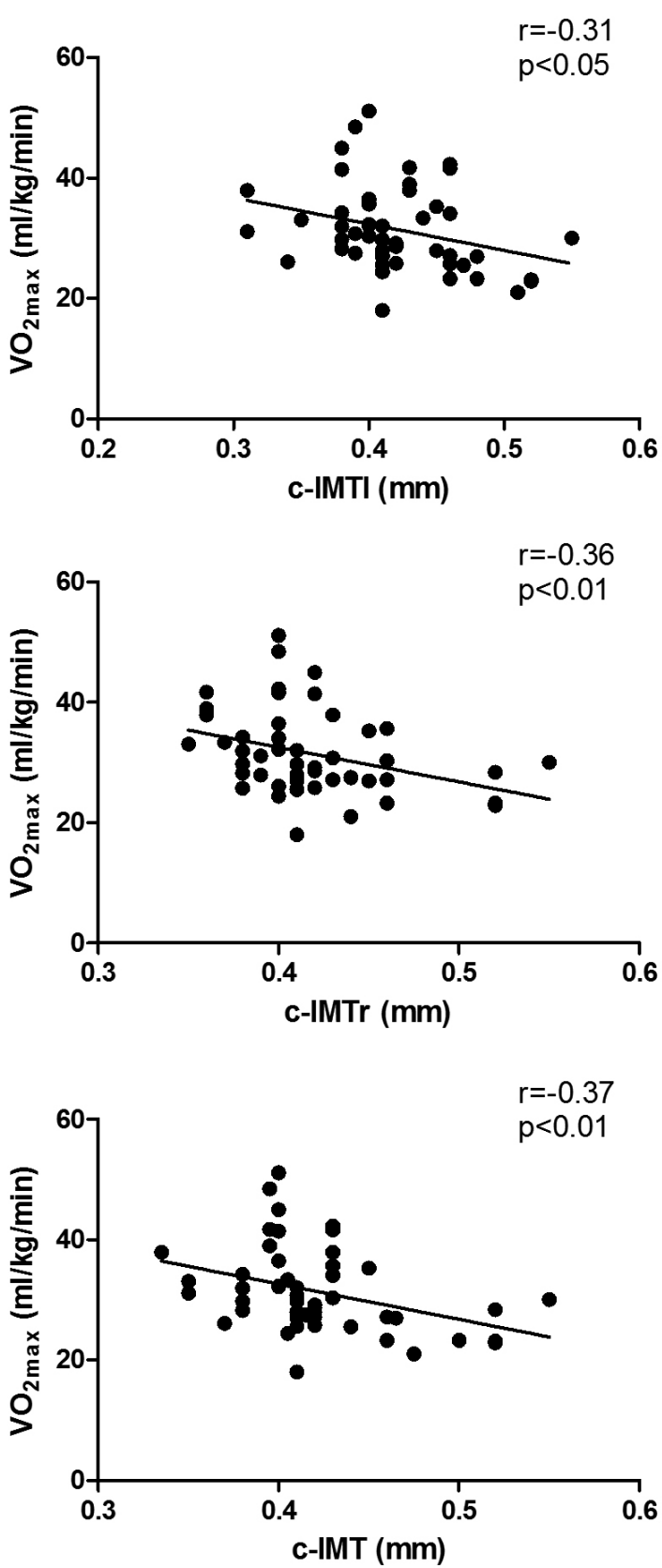

Figure 1. Correlation between maximal oxygen consumption $\left(\mathrm{VO}_{2} \max \right)$ and left-side carotid intima-media thickness (c-IMTl), right-side carotid intima-media thickness (c-IMTr), and carotid intima-media thickness (c-IMT).

It was also weakly correlated with HDL and inversely correlated with TAG. CRP was moderately correlated with TAG and inversely correlated with HDL. Table 3 shows the correlations among the variables.

\section{- Discussion}

In our study, we found that obese children and adolescents presented higher c-IMT values than non-obese ones, corroborating previous studies that reported the contribution of obesity to the development of early atherosclerosis ${ }^{23,24}$. The risk factors for atherosclerosis, such as hypertension, dyslipidemia, diabetes, and insulin resistance, have been demonstrated in adults ${ }^{25-28}$, however information on the association of c-IMT with different risk factors measured in childhood and adolescence is limited and contradictory. In a study conducted by Mangge et al. ${ }^{29}$, BMI was positively correlated with c-IMT. Additionally, Beauloye et al. ${ }^{4}$ found that SBP, insulin, and HOMA-IR were correlated with c-IMT. In contrast, some authors did not find any correlation between c-IMT and cardiovascular risk factors $^{3,30-32}$. In the present study, we found that c-IMT was positively correlated with $\mathrm{BMI}, \mathrm{WC}, \% \mathrm{BF}$, and HOMA-IR and inversely correlated with HDL. These findings are in line with studies demonstrating that obesity, insulin resistance, and dyslipidemia can be associated with an increase in c-IMT in this population $^{33}$.

Recently, inflammation biomarkers have been considered a risk factor for early atherosclerosis ${ }^{4,34,35}$. Elevated PCR and reduced adiponectin levels are known to be more frequent in obese individuals ${ }^{7}$. We found that obese children and adolescents had higher PCR and lower adiponectin levels than non-obese ones. Also, we found that c-IMT was significantly correlated with PCR, but not with adiponectin. CRP is known to affect endothelial function via either direct or indirect mechanisms, such as reducing NO (nitric oxide) production and stimulating inflammationoxidative stress pathways ${ }^{34}$. Moreover, adiponectin promotes the production of NO in endothelial cells, and hypoadiponectinaemia is associated with blunted endothelial function ${ }^{30}$. The lack of NO production induces vasoconstriction, leucocyte adherence, platelet activation, oxidative stress, and thrombosis, leading to endothelial dysfunction ${ }^{34,36}$. The lack of correlation between adiponectin and endothelial dysfunction in obese children and adolescents may be due to different signaling pathways in children and in adults, especially as regards phosphatidylinositol 3-kinase for adiponectin stimulation of NO production in endothelial cells ${ }^{37}$. In addition, the presence of multimetric forms of adiponectin and high-molecular-weight adiponectin is thought to be superior to total adiponectin level in predicting the c-IMT ${ }^{37}$. This was shown by Mangge et al. ${ }^{31}$, who reported that only high-molecular-weight adiponectin was correlated with c-IMT in obese and non-obese children. 
Table 3. Correlations between clinical, laboratory, and anthropometric variables.

\begin{tabular}{|c|c|c|c|c|c|}
\hline Variables & c-IMTr & c-IMTI & c-IMT & Adipo & CRP \\
\hline Weight(kg) & $0.47 * *$ & $0.44 * *$ & $0.46^{* *} *$ & $-0.50 * *$ & 0.29 \\
\hline $\mathrm{WC}(\mathrm{cm})$ & $0.54 * *$ & $0.43 * *$ & $0.47 * *$ & $-0.54 * *$ & $0.38 *$ \\
\hline $\operatorname{SBP}(\mathrm{mmHg})^{\Delta}$ & 0.09 & 0.28 & 0.24 & -0.22 & 0.11 \\
\hline $\mathrm{DBP}(\mathrm{mmHg})^{\Delta}$ & 0.24 & 0.10 & 0.23 & 0.08 & -0.14 \\
\hline$\%$ Body fat & $0.40 * *$ & $0.30 *$ & $0.48^{* *}$ & $-0.44 * *$ & $0.35^{*}$ \\
\hline$\% \mathrm{FFM}$ & $-0.40 * *$ & $-0.30 *$ & $-0.48 * *$ & $0.44 * *$ & $-0.35^{*}$ \\
\hline $\mathrm{VO}_{2} \max (\mathrm{ml} / \mathrm{kg} / \mathrm{m})$ & $-0.36 * *$ & $-0.31 *$ & $-0.37 * *$ & $0.37 *$ & $-0.42 * *$ \\
\hline $\mathrm{TC}(\mathrm{mg} / \mathrm{dl})$ & 0.09 & -0.01 & 0.04 & -0.14 & -0.07 \\
\hline HDL (mg/dl) & $-0.32 *$ & -0.25 & $-0.33^{*}$ & $0.35^{*}$ & $-0.40^{*}$ \\
\hline LDL (mg/dl) & 0.13 & -0.27 & 0.06 & -0.75 & -0.12 \\
\hline TAG (mg/dl) & 0.26 & 0.07 & 0.21 & $-0.34 *$ & $0.38 *$ \\
\hline $\mathrm{GL}(\mathrm{mg} / \mathrm{dl})$ & $0.34 *$ & 0.27 & 0.27 & 0.08 & 0.11 \\
\hline $\mathrm{INS}(\mu \mathrm{UI} / \mathrm{ml})$ & 0.23 & 0.17 & 0.28 & $-0.59 * *$ & 0.22 \\
\hline HOMA-IR & $0.40 * *$ & 0.23 & $0.34 *$ & $-0.55^{* *}$ & 0.22 \\
\hline $\mathrm{CRP}^{\Delta}$ (mg/L) & $0.40 *$ & 0.28 & 0.21 & -0.03 & --- \\
\hline ADIPO ( $\mu \mathrm{g} / \mathrm{ml})$ & -0.14 & -0.22 & -0.17 & --- & -0.03 \\
\hline
\end{tabular}

BMI: body mass index; BMIz: body mass index z-score; WC: waist circumference; SBP: systolic blood pressure; DBP: diastolic blood pressure; \%Body fat: percentage of body fat; \%FFM: percentage of free-fat mass; VO2max: maximum volume of oxygen; c-IMTr: right intima-media thickness; c-IMTl: left intima-media thickness; c-IMT: intima-media thickness mean; TC: total cholesterol; HDL: high-density lipoprotein; LDL: low-density lipoprotein; TAG: triacylglycerides; GL: glycemia; INS: insulinemia; HOMA-IR: Homeostasis Metabolic Assessment; CRP c-reactive protein; ADIPO: adiponectinemia; $\Delta$ variables analyzed using Spearman's correlation; ${ }^{*} \mathrm{p}<0.05 ;{ }^{*} \mathrm{p}<0.01$.

Our main finding was that cardiorespiratory fitness $\left(\mathrm{VO}_{2} \max \right)$ was inversely associated with c-IMT. Studies have reported an inverse association between cardiorespiratory fitness and c-IMT in middle-aged ${ }^{38,39}$ and elderly ${ }^{39}$ individuals. In children and adolescents, only two studies investigated this relationship and the results were contradictory ${ }^{40,41}$. Kim et al ${ }^{40}$ found an inverse significant correlation between $\mathrm{VO}_{2}$ max and maximum IMT in Korean male adolescents. On the other hand, Pahkala et al. ${ }^{41}$ did not find an association between fitness and c-IMT in Finnish adolescents. It is interesting to note that both studies estimated $\mathrm{VO}_{2} \max$ using indirect methods. The gold-standard measure of cardiorespiratory fitness in humans involves direct assessment of peak or maximal oxygen consumption in response to an exercise test. We used the direct method to measure the $\mathrm{VO}_{2} \max$.

Cardiorespiratory fitness is strongly associated with reduced risk of cardiovascular disease and all-cause mortality ${ }^{42}$. There are several plausible mechanisms by which cardiorespiratory fitness might reduce the risk of carotid atherosclerotic vascular disease. Some studies suggest that the effect of exercise on arterial wall thickness is explained by exercise-mediated changes in traditional cardiovascular risk factors, such as adiposity, lipid levels, and blood pressure ${ }^{39}$. High levels of physical activity increase nitric oxide production, which improve vascular function by enhancing vasodilation and vasomotor function in the vessels. It also prevents platelet aggregation and adhesion in the endothelium, enhances fibrinolysis, improves lipid profiles, and reduces blood viscosity and fibrinogen levels, all of which may contribute to slowing the progression of carotid atherosclerotic vascular disease $\mathrm{e}^{39,43}$. In contrast, other studies have demonstrated the impact of exercise on c-IMT regardless of changes in risk factors ${ }^{39,43}$.

The strength of this study is that we assessed values directly by using gas analyzer and ramp protocol. A limitation of our study is that the number of patients was small and we did not analyze boys and girls separately. In order to minimize the possible effects of gender differences on our data, the number of boys and girls was proportional in both groups (around 50\% in each group). Another limitation is that we used the HOMA-IR to assess insulin resistance, which is less accurate than hyperinsulinemic euglycemic clamp. Additionally, we did not measure other isoforms of adiponectin, which could be more 
sensitive to correlation with c-IMT. Finally, the current study did not use a multivariable adjusted model.

The main finding of this study was the inverse correlation between c-IMT and $\mathrm{VO}_{2}$ max, which shows that low aerobic fitness in this age group can be a predictor of the development of increased c-IMT in childhood and adolescence. It also shows that regular physical activity may be a protective factor for atherosclerosis, regardless of the presence of other traditional cardiovascular risk factors and inflammation.

\section{- Conclusion}

Obese children and adolescents had higher values of c-IMT, as well as metabolic and inflammatory profiles. c-IMT correlates not only with body composition, blood lipids, insulin resistance, and inflammation, but also with low $\mathrm{VO}_{2}$ max in children and adolescents. This result confirms the importance of regular physical activity to prevent cardiovascular disease. Further longitudinal studies are needed to determine whether the increase in cardiorespiratory fitness is associated with improvement in c-IMT during adolescence.

The authors declared no conflict of interest.

\section{- Acknowledgements}

The authors wish to thank Fundação para a Ciência e Tecnologia (FCT), Portugal, Coordenação de Aperfeiçoamento de Pessoal de Nivel Superior (CAPES), Brazil, and Conselho Nacional de Desenvolvimento Científico e Tecnológico (CNPq), Brazil, for their funding.

\section{References}

1. McGill HC Jr, Herderick EE, McMahan CA, Zieske AW, Malcolm GT, Tracy RE, et al. Atherosclerosis in youth. Minerva Pediatr. 2002;54:437-47. PMid:12244281.

2. Zhu W, Huang X, He J, Li M, Neubauer H. Arterial intima-media thickening and endothelial dysfunction in obese Chinese children. Eur J Pediatr. 2005;164:33744. PMid:15750804. http://dx.doi.org/10.1007/ s00431-005-1642-y

3. Giannini C, De Giorgis T, Scarinci A, Ciampani M, Marcovecchio ML, Chiarelli F, et al. Obese related effects of inflammatory markers and insulin resistance on increased carotid intima media thickness in pre-pubertal children. Atherosclerosis. 2008;197:448-56. PMid:17681348. http://dx.doi.org/10.1016/j.atherosclerosis.2007.06.023

4. Beauloye V, Zech F, Tran HT, Clapuyt P, Maes M, Brichard SM. Determinants of early atherosclerosis in obese children and adolescents. J Clin Endocrinol Metab. 2007;92:3025-32. PMid:17519311. http://dx.doi. org/10.1210/jc.2007-0619

5. Brasil AR, Norton RC, Rossetti MB, Leao E, Mendes RP. C-reactive protein as an indicator of low intensity inflammation in children and adolescents with and without obesity. J Pediatr (Rio J). 2007;83:477-80.

6. Asayama K, Hayashibe H, Dobashi K, Uchida N, Nakane $\mathrm{T}$, Kodera K, et al. Decrease in serum adiponectin level due to obesity and visceral fat accumulation in children. Obes Res. 2003;11:1072-9. PMid:12972677. http://dx.doi. org/10.1038/oby.2003.147

7. Nishimura R, Sano H, Matsudaira T, Morimoto A, Miyashita Y, Shirasawa T, et al. Changes in body mass index, leptin and adiponectin in Japanese children during a three-year follow-up period: a populationbased cohort study. Cardiovasc Diabetol. 2009;8:30. PMid:19490650 PMCid:PMC2701411. http://dx.doi. org/10.1186/1475-2840-8-30

8. Bouassida A, Chamari K, Zaouali M, Feki Y, Zbidi A, Tabka Z. Review on leptin and adiponectin responses and adaptations to acute and chronic exercise. Br J Sports Med. 2010;44:620-30. PMid:18927166. http://dx.doi. org/10.1136/bjsm.2008.046151

9. Kumar V, Sachdev HP, Khalil A. Noninvasive evaluation of endothelial function and arterial mechanics in overweight adolescents. Indian Pediatr. 2004;41:1105-14. PMid:15591660.

10. Kapuku GK, Harshfield GA, Davis HC, Treiber FA. Early markers of cardiovascular disease. Vascul Pharmacol. 2006;45:277-80. PMid:17011834. http:// dx.doi.org/10.1016/j.vph.2006.08.009

11. Farpour-Lambert NJ, Aggoun Y, Marchand LM, Martin XE, Herrmann FR, Beghetti M. Physical activity reduces systemic blood pressure and improves early markers of atherosclerosis in pre-pubertal obese children. J Am Coll Cardiol. 2009;54:2396-2406. PMid:20082930. http:// dx.doi.org/10.1016/j.jacc.2009.08.030

12. Kuczmarski RJ, Ogden CL, Grummer-Strawn LM, Flegal KM, Guo SS, Wei R, et al. CDC growth charts: United States. Adv Data. 2000;(314)1-27. PMid:11183293.

13. Tanner JM. Normal growth and techniques of growth assessment. Clin Endocrinol Metab. 1986;15:411-51. http://dx.doi.org/10.1016/S0300-595X(86)80005-6

14. National High Blood Pressure Education Program Working Group on High Blood Pressure in Children and Adolescents. The fourth report on the diagnosis, evaluation, and treatment of high blood pressure in children and adolescents. Pediatrics. 2004;114:55576. PMid:15286277. http://dx.doi.org/10.1542/ peds.114.2.S2.555

15. Lohman TG, Roche AF, Martorell R. Anthropometric standardization reference manual. Champaign: Human Kinetics; 1988.

16. Fernandez JR, Redden DT, Pietrobelli A, Allison DB. Waist circumference percentiles in nationally representative samples of African-American, European-American, and Mexican-American children and adolescents. J Pediatr. 2004;145:439-44. PMid:15480363. http://dx.doi. org/10.1016/j.jpeds.2004.06.044 
17. Houtkooper LB, Going SB, Lohman TG, Roche AF, Van Loan M. Bioelectrical impedance estimation of fat-free body mass in children and youth: a cross-validation study. J Appl Physiol. 1992;72:366-73. PMid:1537738.

18. Bioelectrical impedance analysis in body composition measurement: National Institutes of Health Technology Assessment Conference Statement. Am J Clin Nutr. 1996;64(3 Suppl):524S-32. PMid:8780375.

19. American College of Sports Medicine - ACSM. ACSM'S Guidelines for exercise testing and prescription. Philadelphia: Lippincott Williams \& Wilkins; 2006.

20. Leite N, Milano GE, Cieslak F, Lopes WA, Rodacki A, Radominski RB. Effects of physical exercise and nutritional guidance on metabolic syndrome in obese adolescents. Rev Bras Fisioter. 2009;13:73-81. http:// dx.doi.org/10.1590/S1413-35552009005000009

21. Back Giuliano Ide C, Caramelli B, Pellanda L, Duncan B, Mattos S, Fonseca FH. [I guidelines of prevention of atherosclerosis in childhood and adolescence]. Arq Bras Cardiol. 2005;85 Suppl 6:4-36. PMid:16597097.

22. Friedewald WT, Levy R, Fredrickson DS. Estimation of the concentration of low-density lipoprotein cholesterol in plasma, without use of the preparative ultracentrifuge. Clin Chem. 1972;18:499-502. PMid:4337382.

23. Lamotte C, Iliescu C, Libersa CFG. Increased intimamedia thickness of the carotid artery in childhood: a systematic review of observational studies. Eur J Pediatr. 2011;170:719-29. PMid:20978785. http://dx.doi. org/10.1007/s00431-010-1328-y

24. Silva LR, Stefanello JMF, Pizzi J, Timossi LS, Leite N. Atherosclerosis subclinical and inflammatory markers in obese and nonobese Children and adolescents. Rev Bras Epidemiol. 2012;15(4):13. PMid:22450489.

25. Di Pino A, Alagona C, Piro S, Calanna S, Spadaro L, Palermo F, et al. Separate impact of metabolic syndrome and altered glucose tolerance on early markers of vascular injuries. Atherosclerosis. 2012;223(2):45862. PMid:22742860. http://dx.doi.org/10.1016/j. atherosclerosis.2012.05.008

26. Recio-Rodriguez JI, Gomez-Marcos MA, PatinoAlonso MC, Agudo-Conde C, Rodriguez-Sanchez E, Garcia-Ortiz L, et al. Abdominal obesity vs general obesity for identifying arterial stiffness, subclinical atherosclerosis and wave reflection in healthy, diabetics and hypertensive. BMC Cardiovasc Disord. 2012;12:3. PMid:22292502 PMCid:PMC3395841. http://dx.doi. org/10.1186/1471-2261-12-3

27. Wang Y, Ma X, Zhou M, Zong W, Zhang LYH, Zhu $\mathrm{J}$, et al. Contribution of visceral fat accumulation to carotid intima-media thickness in a Chinese population. Int J Obes (Lond). 2012;36(9):51203-8. PMid:22124446 PMCid:PMC3448043. http://dx.doi.org/10.1038/ ijo.2011.222

28. Manios E, Michas F, Tsivgoulis G, Stamatelopoulos K, Tsagalis G, Koroboki E, et al. Impact of prehypertension on carotid artery intima-media thickening: Actual or masked? Atherosclerosis. 2011;214:215-9. PMid:21122854. http:// dx.doi.org/10.1016/j.atherosclerosis.2010.10.032

29. Mangge H, Schauenstein K, Stroedter L, Griesl A, Maerz $\mathrm{W}$, Borkenstein M. Low grade inflammation in juvenile obesity and type 1 diabetes associated with early signs of atherosclerosis. Exper Clin Endocrinol Diabetes. 2004;112(7):378-82. PMid:15239023. http://dx.doi. org/10.1055/s-2004-821023

30. Arnaiz P, Acevedo M, Barja S, Aglony M, Guzmán B, Cassis B, et al. Adiponectin levels, cardiometabolic risk fators and markers of subclinical atherosclerosis in children. Int J Cardiol. 2008;138:138-44. PMid:18774612. http://dx.doi.org/10.1016/j.ijcard.2008.08.007

31. Mangge H, Almer G, Haj-Yahya S, Grandits N, Gasser R, Pilz S, et al. Nuchal thickness of subcutaneous adipose tissue is tightly associated with an increased LMW/total adiponectin ratio in obese juveniles. Atherosclerosis. 2009;203(1):277-83. PMid:18656877. http://dx.doi. org/10.1016/j.atherosclerosis.2008.06.013

32. Kelishadi R, Cook SR, Amrac B, Adibi A. Factors associated with insulin resistance and non-alcoholic fatty liver disease among youths. Atherosclerosis. 2009;204:538-43. PMid:19013572. http://dx.doi. org/10.1016/j.atherosclerosis.2008.09.034

33. Herouvi D, Karanasios E, Karayianni C, Karavanaki K. Cardiovascular disease in childhood: the role of obesity. Eur J Pediatr. 2013;172:721-32. PMid:23340698. http:// dx.doi.org/10.1007/s00431-013-1932-8

34. Higashi Y, Noma K, Yoshizumi M, Kihara Y. Endothelial function and oxidative stress in cardiovascular diseases. Circ J. 2009;73(3):411-8. PMid:19194043. http://dx.doi. org/10.1253/circj.CJ-08-1102

35. Jimenez MV, Estepa RM, Camacho RM, Estrada RC, Luna FG, Guitarte FB. Endothelial dysfunction is related to insulin resistance and inflammatory biomarker levels in obese prepubertal children. Eur J Endocrinol. 2007;156:497-502. PMid:17389466. http://dx.doi. org/10.1530/EJE-06-0662

36. Vanhoutte PM. Endothelial dysfunction: the first step toward coronary arteriosclerosis. Circ J. 2009;73:7. http:// dx.doi.org/10.1253/circj.CJ-08-1169

37. Han SH, Sakuma I, Shin EK, Koh KK. Antiatherosclerotic and anti-insulin resistance effects of adiponectin: basic and clinical studies. Prog Cardiovasc Dis. 2009;52(2):12640. PMid:19732605. http://dx.doi.org/10.1016/j. pcad.2009.06.004

38. Lee CD, Jae SY, Iribarren C, Pettee KK, Choi H. Physical fitness and carotid atherosclerosis in men. Int J Sports Med. 2009;30:672-6. PMid:19569012. http://dx.doi. org/10.1055/s-0029-1224179

39. Thijssen DH, Cable NT, Green DJ. Impact of exercise training on arterial wall thickness in humans. Clin Sci (Lond). 2012;122(7):311-22. PMid:22150253 PMCid:3233305. http://dx.doi.org/10.1042/CS20110469

40. Kim ES, Park J-H, Lee MK, Lee DH, Kang ES, Lee HC, et al. Associations between Fatness, Fitness, IGF and IMT among Obese Korean Male Adolescents. Diabetes Metab J. 2011;35(6):610-8. PMid:22247904 PMCid:PMC3253972. http://dx.doi.org/10.4093/ dmj.2011.35.6.610

41. Pahkala K, Laitinen TT, Heinonen OJ, Viikari JS, Ronnemaa $\mathrm{T}$, Niinikoski H, et al. Association of fitness with vascular intima-media thickness and elasticity in adolescence. 
Pediatrics. 2013;132(1):e77-84. PMid:23753102. http:// dx.doi.org/10.1542/peds.2013-0041

42. Eisenmann JC, Welk GJ, Ihmels M, Dollmlan J. Fatness, fitness, and cardiovascular disease risk factors in children and adolescents. Med Sci Sports Exerc. 2007;39(8):1251-7. PMid:17762357. http://dx.doi. org/10.1249/MSS.0b013e318064c8b0

43. Montero D, Walther G, Perez-Martin A, Roche E, Vinet A. Endothelial dysfunction, inflammation, and oxidative stress in obese children and adolescents: markers and effect of lifestyle intervention. Obes Rev. 2012;13:441-55. PMid:22133012. http://dx.doi. org/10.1111/j.1467-789X.2011.00956.X

\section{Correspondence}

\section{Larissa R. Silva}

Universidade Federal do Paraná

Departmento de Educação Física

Travessa Coração de Maria, 92, BR 116, km 95, Jardim

Botânico

CEP 80215-370, Curitiba, PR, Brazil

e-mail: larisilva99@yahoo.com.br 